\title{
Correspondence
}

\section{The ubiquitin editing enzyme A20 (TNFAIP3) is upregulated during permanent middle cerebral artery occlusion but does not influence disease outcome}

\author{
C Mc Guire ${ }^{1,2}$, M Rahman $^{3}$, M Schwaninger ${ }^{3}$, R Beyaert ${ }^{1,2}$ and G van Loo ${ }^{*, 1,2}$
}

Cell Death and Disease (2013) 4, e531; doi:10.1038/cddis.2013.55; published online 7 March 2013

Subject Category: neuroscience

Dear Editor,

Cerebral ischemia is characterized by the activation of glial cells, causing a rapid and massive local inflammatory reaction that leads to tissue damage and neuronal cell death. ${ }^{1}$ Over the past decade, it has become increasingly clear that the transcription factor nuclear factor $\kappa \mathrm{B}(\mathrm{NF}-\kappa \mathrm{B})$ has a central role in the pathogenesis of cerebral ischemia. The NF- $\kappa \mathrm{B}$ family consists of five members, RelA (p65), RelB, c-Rel, p50 and p52, all of which are activated in the ischemic hemisphere of mice shortly after permanent middle cerebral artery occlusion (pMCAO), a well-established rodent model of focal cerebral ischemia. ${ }^{2}$ Furthermore, p50-deficient mice show a reduction in ischemic damage after pMCAO and transient MCAO followed by reperfusion, suggesting a cell death
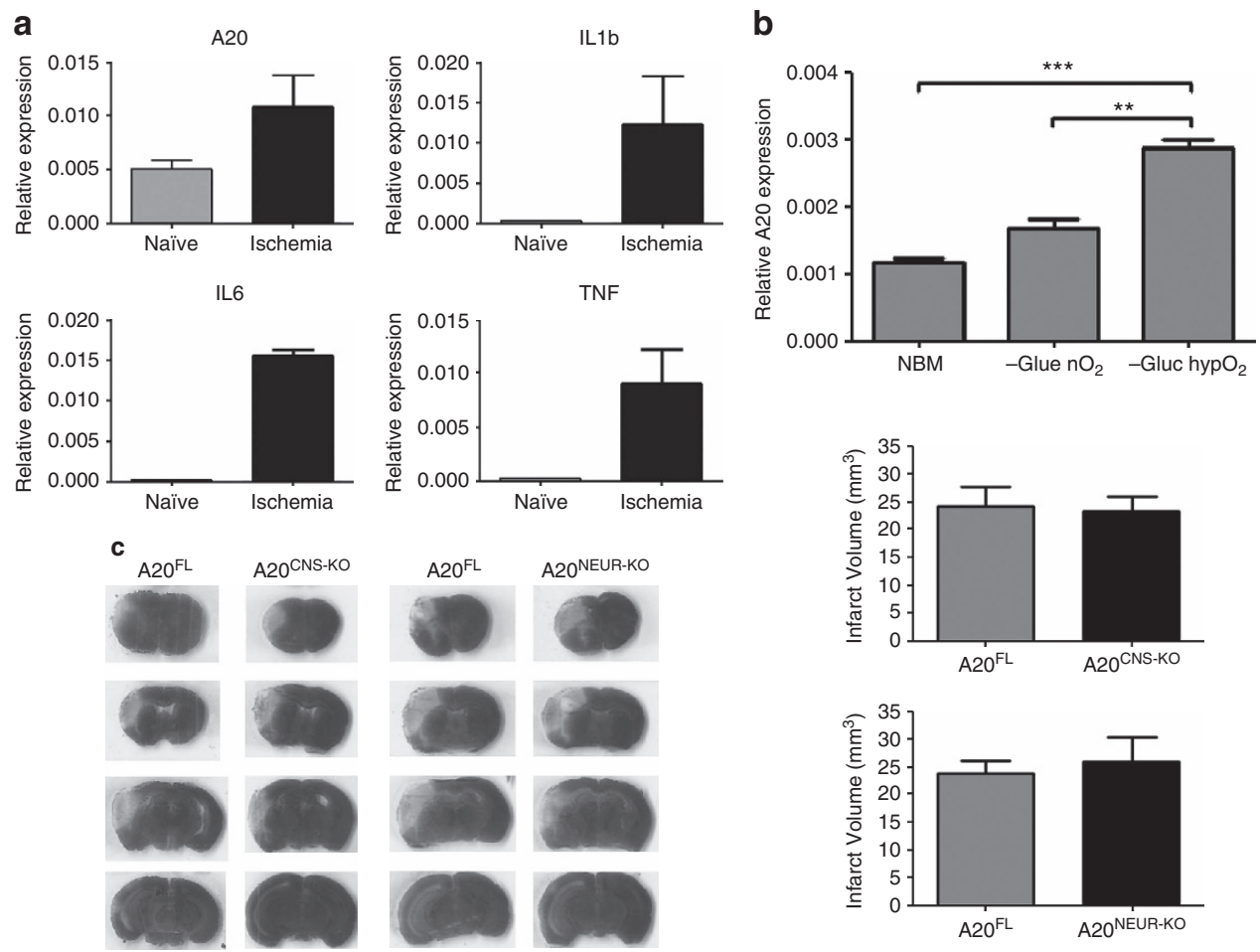

Figure 1 (a) pMCAO was induced in wild-type C57BL/6 mice and gene expression in the infarcted brain area was assessed by quantitative real-time PCR $24 \mathrm{~h}$ after pMCAO. (b) A20 expression in primary cortical neurons, as assessed by quantitative real-time PCR. NBM, neurobasal medium supplemented with $\mathrm{B}^{27}$; -Gluc $\mathrm{nO} \mathrm{O}_{2}$, DMEM without glucose in normoxic conditions; -Gluc hypoO ${ }_{2}$, DMEM without glucose in hypoxic conditions. ${ }^{* \star} P<0.01 ;{ }^{* * \star} P<0.001$ (c) pMCAO was induced in CNS- (A20 ${ }^{\text {CNS-KO }}$, $n=12$ ) or neuron-specific (A20 $\left.{ }^{\mathrm{NEUR}-\mathrm{KO}}, n=6\right)$ A20-deficient mice and their control A20 ${ }^{\mathrm{FL}}$ littermates $\left(n=9\right.$ and $n=12$, respectively), as previously described. ${ }^{2}$ Representative silver-stained brain sections (left panel) and evaluation of infarcts volume (right panel) $24 \mathrm{~h}$ after pMCAO. Values are means \pm S.E.M.

\footnotetext{
${ }^{1}$ Department for Molecular Biomedical Research, Unit of Molecular Signal Transduction in Inflammation, VIB, Ghent University, B-9052 Ghent, Belgium; ${ }^{2}$ Department of Biomedical Molecular Biology, Ghent University, B-9052 Ghent, Belgium and ${ }^{3}$ Institute of Experimental and Clinical Pharmacology and Toxicology, University of Lübeck, D-23538 Lübeck, Germany

${ }^{*}$ Corresponding author: G van Loo, Department for Molecular Biomedical Research, Unit of Molecular Signal Transduction in Inflammation, VIB, Ghent University, Technologiepark 927, B-9052 Ghent, Belgium. Tel: + 329331 3761; Fax: + 329221 7673; E-mail: geert.vanloo@dmbr.vib-ugent.be
} 
promoting role for NF- $\kappa \mathrm{B}$ in this model. ${ }^{3,4}$ In addition, mice lacking RelA in the central nervous system (CNS) also show reduced infarct size after $48 \mathrm{~h}$ of pMCOA, whereas germline deletion of the p52 or c-Rel subunits did not affect infarct volume. $^{2}$ In line with findings that NF- $\kappa$ B has a detrimental role during ischemia, mice lacking IKK2 in all neuroectodermal cells or specifically in neurons show a decreased infarct volume $48 \mathrm{~h}$ after $\mathrm{PMCAO}$, whereas constitutive activation of IKK2 increased infarct size. ${ }^{5}$ However, NF- $\kappa$ B may also act beneficial in conditions of ischemic preconditioning, which was shown to protect against a subsequent prolonged ischemic insult through transcriptional activation of NF- $\kappa \mathrm{B} .{ }^{6}$

The ubiquitin editing enzyme A20 is a key negative regulator of NF- $\kappa \mathrm{B}$ signaling. Moreover, A20 can also act as a strong antiapoptotic protein in specific cell types. ${ }^{7}$ Because of the central role of $\mathrm{A} 20$ in controlling NF- $\kappa \mathrm{B}$ and apoptotic responses, we sought to further clarify its in vivo role in the pMCAO mouse model of brain ischemia.

We demonstrate here that $\mathrm{NF}-\kappa \mathrm{B}$ driven genes such as $A 20, T N F$ and $I L-6$ are upregulated in the infarcted area $24 \mathrm{~h}$ post pMCAO (Figure 1a). We further questioned whether A20 would be differentially regulated in primary murine cortical neurons after glucose oxygen deprivation, an in vitro model mimicking pMCAO. In agreement with our in vivo data, A20 mRNA was upregulated in primary murine cortical neurons when placed in a glucose deprived $0.1 \% \quad \mathrm{O}_{2}$ hypoxic environment for $4 \mathrm{~h}$ (Figure $1 \mathrm{~b}$ ). As A20 is upregulated both in vivo and in vitro during ischemic conditions, we questioned whether mice lacking A20 specifically in the CNS (A20 CNS-KO) or exclusively in neurons (A20 NEUR-KO) are affected differently after pMCAO when compared with wild-type littermates. $\mathrm{A} 20^{\mathrm{CNS}-\mathrm{KO}}$ and $\mathrm{A} 20^{\mathrm{NEUR}-\mathrm{KO}}$ mice were generated by crossing mice carrying a floxed $A 20$ allele ${ }^{8}$ to mice expressing crerecombinase under control of the nestin or thy 1.2 promoter, respectively. These $\mathrm{A} 20^{\mathrm{CNS}-\mathrm{KO}}$ or $\mathrm{A} 20^{\mathrm{NEUR}-\mathrm{KO}}$ mice, together with control littermate mice, were subjected to $\mathrm{pMCAO}$ for $24 \mathrm{~h}$ after which the infarct size was estimated by means of a silver staining technique. To our surprise the infarct volume did not differ between $\mathrm{A} 2 \mathrm{O}^{\mathrm{CNS}-\mathrm{KO}}$ or A20 $\mathrm{N}^{\mathrm{NEUR}-\mathrm{KO}}$ and their respective wild-type control littermates (Figure 1c). Collectively, these results clearly demonstrate that, although $A 20$ is upregulated in conditions of pMCAO, A20 deficiency in either all cells of neuroectodermal origin, or more specifically in neurons, does not influence the outcome of pMCAO in mice.

\section{Conflict of Interest}

The authors declare no conflict of interest.

Acknowledgements. We are grateful to $\mathrm{Dr}$ Diether Lambrechts (VIB Vesalius Research Center, Leuven, Belgium) for providing the thy1.2Cre mice. C Mc Guire was supported as a PhD fellow with the 'Fonds voor Wetenschappelijk Onderzoek-Vlaanderen' (FWO). G van Loo was supported by an FWO Odysseus Grant and by grants from the 'Geneeskundige Stichting Koningin Elisabeth' (GSKE) and the Charcot Foundation.

\footnotetext{
1. Ridder DA, Schwaninger M. Neuroscience 2009; 158: 995-1006.

2. Inta I et al. J Neurosci 2006; 26: 12896-12903.

3. Nurmi A et al. Stroke 2004; 35: 987-991.

4. Schneider A et al. Nat Med 1999; 5: 554-559.

5. Herrmann $\mathrm{O}$ et al. Nat Med 2005; 11: 1322-1329.

6. Blondeau N et al. J Neurosci 2001; 21: 4668-4677.

7. Ma A, Malynn BA. Nat Rev Immunol 2012; 12: 774-785.

8. Vereecke L et al. J Exp Med 2010; 207: 1513-1523.
}

(c) $(1)(9) \Theta$ Cell Death and Disease is an open-access journal published by Nature Publishing Group. This work is licensed under a Creative Commons Attribution-NonCommercialNoDerivs 3.0 Unported License. To view a copy of this license, visit http://creativecommons.org/licenses/by-nc-nd/3.0/ 